\title{
In silico mechanistic assessment of imaging-based measures of cardiac (patho) physiology
}

Citation for published version (APA):

Palau Caballero, G. (2017). In silico mechanistic assessment of imaging-based measures of cardiac (patho) physiology. [Doctoral Thesis, Maastricht University]. Universitaire Pers Maastricht. https://doi.org/10.26481/dis.20170127gpc

Document status and date:

Published: 01/01/2017

DOI:

10.26481/dis.20170127gpc

Document Version:

Publisher's PDF, also known as Version of record

\section{Please check the document version of this publication:}

- A submitted manuscript is the version of the article upon submission and before peer-review. There can be important differences between the submitted version and the official published version of record. People interested in the research are advised to contact the author for the final version of the publication, or visit the DOI to the publisher's website.

- The final author version and the galley proof are versions of the publication after peer review.

- The final published version features the final layout of the paper including the volume, issue and page numbers.

Link to publication

\footnotetext{
General rights rights.

- You may freely distribute the URL identifying the publication in the public portal. please follow below link for the End User Agreement:

www.umlib.nl/taverne-license

Take down policy

If you believe that this document breaches copyright please contact us at:

repository@maastrichtuniversity.nl

providing details and we will investigate your claim.
}

Copyright and moral rights for the publications made accessible in the public portal are retained by the authors and/or other copyright owners and it is a condition of accessing publications that users recognise and abide by the legal requirements associated with these

- Users may download and print one copy of any publication from the public portal for the purpose of private study or research.

- You may not further distribute the material or use it for any profit-making activity or commercial gain

If the publication is distributed under the terms of Article $25 \mathrm{fa}$ of the Dutch Copyright Act, indicated by the "Taverne" license above, 


\section{Summary}

Cardiovascular diseases are the leading cause of death in the Western world. Treatment strategies for these diseases are often based on a 'one-size-fits-all' approach because findings from large clinical trials determine guideline recommendations and, hence, clinical decision-making. While a statistically significant majority of patients may benefit from a particular therapy, differences between individuals can have great impact on outcome and efficacy of a specific therapy in the individual patient. Recognition of differences between patients treated with the same therapy has led to an upsurge of interest in personalised medicine in recent years, in which selection of appropriate and optimal therapies is based on the patient's pathophysiological profile.

Unfortunately, accurate and objective phenotyping of a patient is difficult because it requires understanding of the functional interplay between structural and functional properties of the cardiovascular system. Gaining this understanding is challenging in the clinical setting due to the inherent inability to evaluate the isolated impact of a given patient-specific variable on cardiac function. Computer modelling of the human heart and circulatory system is an emerging field that can offer mechanistic insight into cardiovascular function and unravel mechanisms underlying cardiac (patho)physiology. In this thesis, we used the multi-scale CircAdapt computational model to explore how variations in physiology between patients can lead to abnormal imaging-based observations in three specific clinical conditions: aortic regurgitation, pulmonary arterial hypertension, and intense exercise.

Chapter 2 gives an overview of the modelling tools used in this thesis. It provides a general description of the CircAdapt model that we used to simulate heart and circulatory dynamics, together with the physical and physiological principles underlying the model. We focus on the elements and properties of the CircAdapt model that are of greatest importance for this thesis, namely cardiac cavities and valves, large blood vessels, and systemic and pulmonary circulations. Furthermore, we demonstrate that CircAdapt can provide realistic simulations of adult circulatory physiology in terms of pressures, flows, blood volumes, and tissue mechanics.

Aortic regurgitation $(A R)$ is a backwards flow of blood from the aorta into the left ventricle caused by a leaky aortic valve. AR severity is assessed clinically through imaging-based indices. Severity quantification is complicated by the hemodynamic interaction between the heart and the aorta, whose tissue properties can vary between pa- 
tients and may influence the indices used for severity assessment. Improved understanding of how a patient's individual physiology can influence conventional AR severity indices can therefore help to personalize decision-making and treatment for patients with AR. In chapter 3 , we systematically investigated how both AR severity indices and the hemodynamic consequences of $A R$ are influenced by inter-patient differences in aortic and left ventricular (LV) stiffness. Our simulations showed that altered AR hemodynamics caused by variations in cardiovascular tissue properties led to inconsistent AR severity scores using conventional indices such as regurgitant fraction (RF), regurgitant volume, and pressure half-time (PHT). Furthermore, pulmonary congestion was poorly reflected by AR severity as quantified by the regurgitant orifice area, RF, and PHT. Cardiac and aortic tissue properties should therefore be taken into account to personalize clinical assessment of AR severity.

Rapid leftward septal motion (RLSM) during early LV diastole is observed in patients with pulmonary arterial hypertension (PAH). PAH is a condition wherein the pulmonary blood vessels become abnormally stiff and narrow, placing the right side of the heart under an increasingly high stress ('afterload'). RLSM is associated with exacerbation of right ventricular (RV) systolic dysfunction and impairment of LV filling. Increased RV wall tension caused by increased RV afterload has been suggested to cause interventricular relaxation dyssynchrony and RLSM in PAH, but measurements of ventricular mechanics are crucial to conclusively demonstrate that this is the case. In chapter 4, we used the CircAdapt simulations to unravel the mechanism underlying RLSM by mechanistically linking regional myocardial tissue mechanics to global ventricular pump function. We performed simulations of the healthy circulation and increasing degrees of PAH. We also assessed the effects on RLSM when PAH coexists with RV or LV hypo- and hypertrophy. Our results showed prolonged RV shortening in PAH causing interventricular relaxation dyssynchrony and RLSM. RLSM was observed in both moderate and severe $\mathrm{PAH}$, while a negative transseptal pressure gradient only occurred in severe $\mathrm{PAH}$. This suggests that RLSM cannot be explained by a negative pressure gradient alone, as has been hypothesized previously. Instead, dyssynchrony in ventricular relaxation determines RLSM in PAH. Furthermore, PAH coexisting with RV hypotrophy exacerbated both interventricular relaxation dyssynchrony and RLSM, whereas LV hypotrophy reduced both. Onset of RLSM in patients with PAH appears to indicate a worsening in RV function and, hence, can be used as sign of RV failure. However, a reduction of RLSM can result from either improved RV function or a deterioration of LV function. Considering the function of the whole heart can therefore help to assess the significance of the presence or absence of RLSM in the individual patient.

Exercise-induced RV dysfunction and disproportionate increases in pulmonary pressures have been associated with adverse RV remodelling. In chapter 5 , we aimed to gain mechanistic insight into the complex circulatory physiology during intense exercise. We hypothesized that exercise-induced changes in RV myocardial function limit cardiopulmonary exercise capacity. The CircAdapt computational model was used to simulate 
cardiovascular dynamics during exercise and, hence, to explore exercise-induced changes in cardiopulmonary function. We evaluated the effects of cardiac training and inotropy that can affect RV contractile function, as well as pericardial constraint that can modulate ventricular interaction. Raised mean pulmonary arterial pressure (mPAP) during exercise induced prolonged RV contraction relative to the LV. This led to interventricular relaxation dyssynchrony and early-diastolic RLSM at high-intensity exercise that was strikingly similar to the RLSM observed at rest in the setting of PAH. Mean left atrial and left ventricular filling pressures raised tremendously with exercise intensity. Interventions enhancing cardiac contractility through cardiac training or inotropy normalized the increases in MPAP and septal dynamics at intense exercise, whereas stiffening of the pericardium led to the opposite effect. Our simulation results show that the exercise-induced increase in RV afterload led to impaired cardiac function and earlydiastolic abnormal septal motion. Factors strengthening RV contractile function improved global cardiac function during intense exercise. The latter suggests that RV myocardial dysfunction limits an individual's cardiovascular exercise capacity.

Our simulation results from chapter 5 in combination with state-of-the-art magnetic resonance imaging data from highly trained athletes at near-peak exercise led us to propose our novel hypothesis on cardiovascular exercise capacity in chapter 6 . Interactions between the left and the right sides of the heart, be it direct mechanical interaction through the septum, indirect hemodynamic interaction through the pulmonary circulation, or the combination of both, can lead to a vicious cycle of RV dysfunction during extreme intensity exercise, as demonstrated by the presence of exerciseinduced RLSM post-race in some endurance athletes. The novel concept of cardiopulmonary limitation during intense exercise with its pivotal role for RV myocardial function adds new perspectives on the mechanisms underlying inter-individual variation in exercise capacity, including the marked exercise limitation evident in patients with $\mathrm{PAH}$.

The findings of this thesis demonstrate the important value of in silico investigations into human (patho)physiology as they can aid the interpretation of cardiovascular system function. By investigating complex but relevant cardiac and vascular interactions and their impact on cardiac function, we unravelled mechanisms underlying diagnostic observations based on imaging in each of the aforementioned clinical conditions. Given the potential clinical significance of the findings outlined above, we conclude that understanding the mechanisms underlying observations from imaging is critical for proper personalization of clinical decision-making based on these diagnostic observations. It therefore follows that computer models can help to personalize medicine without necessarily requiring the construction of a personalized model. 
